\title{
Laparoscopic case series
}

\author{
KB Galketiya ${ }^{1}$, SS Edirimuni ${ }^{2}$ \\ ${ }^{I}$ Consultant Surgeon, ${ }^{2}$ Senior Registrar in Surgery, General Surgery Unit I, Teaching Hospital \\ Karapitiya, Galle.
}

\section{Introduction}

Cholecystectomy, appendicectomy and diagnostic procedures are commonly performed laparoscopically. However, the list of procedures being performed by laparoscopy is expanding. Laparoscopic approach has minimal morbidity related to the exposure (wound) such as pain, bleeding and incisional hernia [1,2]. A collection of case histories and discussions where laparoscopy was used as the surgical technique are presented below.

\section{Case 1 - Recurrent direct inguinal hernia}

A 64 year-old man presented with a right direct inguinal hernia which had been operated on twice before. On the last occasion a polypropylene mesh was used for the repair. He underwent a laparoscopic total extra-peritoneal repair with a satisfactory outcome.

In this case the dissection was done through undisturbed tissue planes. This avoids the difficult dissection of open hernia repair through distorted and fibrosed anatomical planes [3].

\section{Case 2 - Laparoscopic splenectomy}

A 25 year-old girl with immunethrombocytopaenic purpura underwent laparoscopic splenectomy. Since in ITP the spleen is smaller than normal, it was retrieved into an endobag and pulled out through a small (transverse) incision. The operating time was 3 hours, which is longer than in an open surgery.

\section{Case 3 - Laparoscopic fundoplication}

A 54 year-old man with gastro-oesophageal reflux disease persisted to have volume reflux despite treatment with proton pump inhibitors and prokinetic drugs. He was carefully evaluated and a laparoscopic Nissen fundoplication was performed. His reflux settled but complained of dysphagia, a known complication of the procedure [3]. After one month from surgery his dysphagia settled. However, an upper gastrointestinal endoscopy was done which demonstrated gastro-oesophageal junction at $40 \mathrm{~cm}$ and surgically created valve like appearance on J manoeuvre.

\section{Case 4 - Laparoscopy assisted right}

\section{hemicolectomy}

A 42 year-old man with a carcinoma caecum underwent laparoscopic mobilization of the caecum, ascending colon and proximal transverse colon. Exteriorization of the bowel was done through a small incision and an extracorporeal anastomosis performed. The operating time was 3 hours and blood loss was about $100 \mathrm{ml}$.

\section{Case 5 - Laparoscopic assisted}

\section{abdominoperineal resection}

A 73 year-old man with a rectal carcinoma underwent the above procedure. Laparoscopic mobilization of the recto-sigmoid was followed by (open) perineal resection. The sigmoid colon was transected through a small incision in the left iliac fossa which was later used to create the sigmoid colostomy. The resected bowel was delivered through the perineal incision. Operating time was $5 \mathrm{hrs}$. He had an uneventful recovery.

\section{Case 6 - Thoraco-Laparoscopic oesophagectomy}

A 44 year-old lady with a moderately differentiated squamous cell carcinoma of the oesophagus underwent the above procedure. The thoracic oesophagus was mobilized by thoracoscopy using 3 ports.

The stomach was mobilized by laparoscopy preserving right gastric and right gastro-epiploic 


\section{Case Reports}

arteries. The cervical oesophagus was mobilized through a neck incision. The mobilized stomach and thoracic oesophagus were pulled into the neck. The stomach was divided $3 \mathrm{~cm}$ distal to the tumour. The cervical oesophagus was divided and gastro-oesophageal anastomosis performed in the neck. A feeding jejunostomy was placed assisted by laparoscope. The operating time was 5 hours and blood loss was $250 \mathrm{ml}$. There were no major incisions in the abdomen and chest. An intercostal tube was placed which drained $50 \mathrm{ml}$ during the first 24 hours. Operative time was 6 hrs and patient had an uneventful recovery.

\section{References}

1. Darzi A. Minimal Access Surgery. In: Kirk RM, Mansfield AO, Cochrane JP Seds. Clinical Surgery in General. Churchill Livingstone, 1999; 240-244.

2. Cushieri A, Houston G. Minimal access therapy. In: Cushieri A, Steele RJC, Moossa A Reds. Essential Surgical Practice. London: Arnold, 2001; 493-520.

3. Palanivelu C. CIGES Atlas of Laparoscopic Surgery. Jaypee Brothers 2003; 3-32. 